\title{
Early Assessment of Cost-effectiveness of Gastric Electrical Stimulation for Diabetic Nausea and Vomiting
}

\author{
Mette W Klinge, ${ }^{1,2 *}$ Peter Rask, ${ }^{2}$ Lene S Mortensen, ${ }^{3}$ Kathrine Lassen, ${ }^{4}$ Niels Ejskjaer, ${ }^{1}$ Lars H Ehlers, ${ }^{4}$ and Klaus Krogh $^{1}$ \\ Departments of ${ }^{1}$ Hepatology and Gastroenterology, ${ }^{2}$ Abdominal Surgery, and ${ }^{3}$ Endocrinology and Internal Medicine, Aarhus University Hospital, \\ Aarhus, Denmark; and ${ }^{4}$ Danish Center for Healthcare Improvements, Aalborg University, Aalborg; Denmark
}

\section{Background/Aims}

Recurrent nausea and/or vomiting are common complications of diabetes mellitus. The conditions severely impact the quality of life of patients and often cause repeated admissions to hospital incurring significant healthcare costs. If standard treatment fails, gastric electrical stimulation (GES) may be offered in selected cases, as a minimally invasive, but expensive, therapeutic option. Our aims are to evaluate the clinical effect and the cost-utility of GES as a treatment for severe diabetic recurrent nausea and/or vomiting.

\section{Methods}

Among 33 diabetes patients implanted with GES because of recurrent nausea and/or vomiting, 30 were available for evaluation. The effect of treatment was assessed prospectively using symptom-diaries and the SF-36 questionnaires at baseline, after 6 and 12 months, and thereafter yearly. The number of days in hospital due to symptoms related to gastrointestinal dysfunction was calculated using hospital records 12 months prior to and 12 months after implantation.

\section{Results}

The surgical procedures were performed without mortality or major complications. Six months after surgery $78 \%$ of the respondents had at least 50\% reduction in time with nausea and $48 \%$ had at least 50\% reduction in days with vomiting. Symptom relief persisted at follow-up after at least 4 years. Quality adjusted life years improved after GES, which was cost-effective after 24 months.

\section{Conclusions}

GES reduces symptoms and improves quality of life in diabetes patients with recurrent nausea and/or vomiting. The procedure is supposed as cost-effective over a 2-year time horizon.

(J Neurogastroenterol Motil 2017;23:541-549)

Key Words

Diabetes mellitus; Electrical stimulation; Health care costs; Nausea; Vomiting

Received: October 15, 2016 Revised: January 4, 2017 Accepted: February 27, 2017

(a) This is an Open Access article distributed under the terms of the Creative Commons Attribution Non-Commercial License (http://creativecommons. org/licenses/by-nc/4.0) which permits unrestricted non-commercial use, distribution, and reproduction in any medium, provided the original work is properly cited.

*Correspondence: Mette W Klinge, MD Department of Hepatology and Gastroenterology, Aarhus University Hospital, Noerrebrogade 44, building 1C, 1st floor, 8000 Aarhus C, Denmark Tel: +45-78462800, Fax: +45-78462820, E-mail: meteader@rm.dk 


\section{Introduction}

Gastroparesis (GP) is defined as a chronic gastric emptying disorder with absence of mechanical obstruction. ${ }^{1}$ The 3 main groups of GP are diabetic, postsurgical, and idiopathic. The clinical characteristics of diabetes related GP include recurrent nausea and/ or vomiting, early satiety, bloating, and abdominal pain. Symptoms of GP typically occur at least 10 years after diagnosis of diabetes mellitus (DM). ${ }^{2}$ The estimated 10-year cumulative incidence of symptomatic GP is $5 \%$ in type $1 \mathrm{DM}$ and $1 \%$ in type $2 \mathrm{DM}^{3}$ The condition is associated with significantly reduced quality of life and frequent admissions to hospital because of recurrent vomiting leading to dehydration and poor glycaemic control. ${ }^{4}$ The pathophysiology of diabetic GP is not fully established, but it is associated with neuropathy of extrinsic and intrinsic neurons, abnormal function of smooth muscle cells, and neuropathy of glia cells and the interstitial cells of Cajal. ${ }^{5}$ The majority of diabetes patients with delayed gastric emptying remain asymptomatic, and severe symptoms can be present even if gastric emptying tests are normal. ${ }^{6}$ Thus, treatment is usually initiated based on recurrent episodes of nausea and/or vomiting rather than a diagnosis of GP based on gastric emptying tests.

Dietary modifications are the first line of intervention for recurrent nausea and/or vomiting in diabetes patients. This is often insufficient and treatment is supplemented with prokinetics and antiemetics. If medical therapy fails, gastric electrical stimulation (GES) is a minimally invasive option. More extensive surgical procedures are only rarely performed as their rate of success is low and complications are common. ${ }^{7}$ Previous studies have shown that GES reduces nausea and/or vomiting and improves quality of life in patients with DM. ${ }^{8-11}$ GES is performed by a laparoscopic procedure and usually only requires a few days in the hospital. The stimulator is, however, relatively expensive and previous analysis of cost-utility was based on very few patients who mainly had idiopathic GP. ${ }^{12}$ Results from patients with idiopathic GP may not be directly applicable to patients with symptoms due to DM, as this group demonstrates progression in their condition, and often other diabetes related complications might be present. Although definitive assessment of costeffectiveness may require long-term evidence from randomized trials, it is important early in the life-cycle of new technologies to begin to estimate likely cost-effectiveness. ${ }^{13}$ Such estimates can help prioritize new research and inform early adopters of the technology. ${ }^{13,14}$ Thus, the aims of the present study were to assess the clinical effects of GES and to perform an early cost-utility analysis of GES for severe recurrent nausea and/or vomiting in patients with DM.

\section{Materials and Methods}

\section{Patients}

Between August 2005 and August 2013, 33 diabetes patients (16 men, median age 41 [range 23-75] years) with severe recurrent nausea and/or vomiting had a gastric electrical stimulator (Enterra Therapy; Medtronic Inc, Minneapolis, MN, USA) implanted at the Department of Abdominal Surgery, Aarhus University Hospital, Aarhus, Denmark. The department is currently the only one in Denmark performing this procedure.

All patients had a history of recurrent episodes of severe nausea and/or vomiting for more than 12 months and none had sufficient relief of symptoms after dietary instructions and medical treatment for a minimum of 6 months. None of the patients had a history of major abdominal surgery and all had undergone standard evaluation including upper endoscopy.

\section{Pre-operative Gastric Emptying Tests}

Since the first GES was implanted at our department in 2005, the gastric emptying tests used had been refined from the radiopaque meal, to the paracetamol absorption test, and finally gastric emptying scintigraphy. Thus, gastric emptying was assessed using a radiopaque meal in 7 (4 prolonged), paracetamol absorption test in 18 (7 prolonged), or gastric emptying scintigraphy in 5 patients (1 prolonged). The paracetamol absorption test and gastric emptying scintigraphy were performed according to previously published protocols. ${ }^{15,16}$ The radiopaque meal consisted of a veal steak, potatoes, sauce, and a glass of X-ray contrast. It was performed after at least 3 hours fasting with radiolucency performed for 2-3 minutes at baseline and again after 6 hours.

\section{Surgical Procedure}

The GES was implanted under laparoscopic guidance under general anaesthesia. Access was through the umbilicus followed by a $5-\mathrm{mm}$ port in the right flank and a $12-\mathrm{mm}$ port in the lower left quadrant. Two intramuscular electrodes (Medtronic model 4351; Medtronic, Inc) were placed $1 \mathrm{~cm}$ apart along the major curvature approximately $10 \mathrm{~cm}$ from the pylorus. Upper endoscopy was performed to ensure that the electrodes had not penetrated the gastric mucosa. The leads from the electrodes were extracted through the port in the lower left quadrant and connected to the pulsestimulator (Medtronic model 3116; Medtronic, Inc). The pulsestimulator was placed subcutaneously and sutured to the abdominal 
fascia to the left of the umbilicus. A standard program was set for the stimulator (standard: Medtronic N'vision 8840; Medtronic, Inc; intensity $5 \mathrm{~mA}$, frequency $14 \mathrm{~Hz}$, pulse width 330 microseconds, cycle on 0.1 seconds, cycle off 5 seconds).

Pre-operatively $1500 \mathrm{mg}$ of cephalosporin was given intravenously and gentamicin sulphate was placed locally over the stimulator. Post-operatively, the patients were restricted to a liquid diet for 24 hours until discharged on their usual diet. If the patients did not have symptom relief the intensity of the current was increased from $5 \mathrm{~mA}$ to $10 \mathrm{~mA}$ during follow-up at our outpatients' hospital after 1, 3,6 , and 12 months and hereafter yearly.

\section{Assessment of Symptoms and Quality of Life}

The symptoms were evaluated by having patients fill in a diary for 2 weeks before GES-surgery (baseline), 6 and 12 months post-surgery, and hereafter every year. The diaries were sent to the patients by mail or issued at scheduled visits in the outpatient's hospital. The diaries included: episodes of vomiting (episodes/day), number of hours with nausea (hours/day), satiety (graded on a scale from 0 to 4 , where 0 represents no satiety and 4 represents severe satiety), bloating ( 0 represents no bloating and 3 represents severe bloating), and general well-being ( 0 represents a state where the patient is able to do whatever she/he likes and 4 represents a miserable state where the patient is confined to bed). Vomiting was defined as a forceful expulsion of the contents of the stomach through the mouth. Reiterate expulsions at the same time only counted as one episode of vomiting.

Alongside the diaries patients filled in the Short Form 36 health survey (SF-36). SF-36 is divided into 8 domains, which were added into the 2 summary scores: a physical component summary score and a mental component summary score. In each, 0 represents worst and 100 the best function (SF-36 version 1; RAND Corporation, Santa Monica, CA, USA; http://www.rand.org/health/ surveys tools $/ \mathrm{mos} / \mathrm{mos}$ core 36 item.html).

In the present paper, all data are given at baseline, 6, and 12 months after surgery, and at long-term which is the longest followup for each individual with a follow-up of at least 4 years. Our predefined main criteria for success were: (1) at least $50 \%$ reduction in time with nausea and (2) at least $50 \%$ reduction in the number of episodes with vomiting.

The study fulfilled the criteria within the Helsinki II declaration and was approved by the Danish Data Protection Agency (Ref. No. 2007-58-0010).

\section{Cost-utility Analysis}

In order to generate quality adjusted life years (QALYs), SF36 data were converted to SF-6D using the algorithm by Brazier et al. ${ }^{17}$ Single imputation was used on missing data points. The total cost for the GES procedure was composed of the device cost, surgical procedure, 3 days of hospital admission in relation to surgery, 5 out-patient visits before or after surgery, and costs for pre-operative endoscopy (Table 1). As 1 re-operation was performed in 1 of our 30 patients, $1 / 30$ of the surgical costs for that were added to all.

One of the authors (L.S.M.) read hospital records of all the patients in this study and counted the number of days in hospital due to symptoms related to gastrointestinal dysfunction for 12 months prior to surgery and for 12 months after. Costs of hospital contacts were calculated from Danish diagnose related group (DRG) rates as given by the Danish healthcare authorities for the year of $2016 .^{18}$ According to these, the average cost of one day in hospital for a patient with the diagnosis DE108 (Type 1 diabetes with complication unspecified) or DE118 (Type 2 diabetes with complication unspecified) is 742 Euros ( $€$ ). The DRG has a set trim point at 11 days, meaning that if patients are continuously in hospital for more than 11 days, a lower extensive-stay rate of $€ 265$ is used. All costs were reported in Euros $(1 €=7.45$ Danish kroner).

Table 1. Cost of Gastric Electrical Stimulation for Diabetes Patients With Recurrent Symptoms of Nausea and/or Vomiting.

\begin{tabular}{lccc}
\multicolumn{1}{c}{ Service } & Cost $(€)$ & No. & Total cost $(€)$ \\
\hline Pre-operative outpatients hospital visit & 76 & 1 & 76 \\
Upper endoscopy & 410 & 1 & 410 \\
GES device & 13.423 & 1 & 2.416 \\
Laparoscopy & 2.416 & 1 & 868 \\
Post-operative follow-up visit in outpatients hospital & 217 & 4 & 81 \\
Re-operation for electrode adjustment & 2.416 & 3 & 2.226 \\
In hospital days related to surgery & 742 & & 19.500 \\
Total cost per patient & & & \\
\hline
\end{tabular}

GES, gastric electrical stimulation.

Costs are given in Euros $(€)$. 
To test for uncertainties in the sample population, bootstrap resampling was performed on both costs and effects at baseline, at 12 months, and for an estimated 24-month's sample. For each parameter the sample was re-sampled 500 times and confidence intervals for the mean were calculated. An incremental cost-effectiveness ratio (ICER) scatterplot was made to visualize the data in relation to an assumed Danish willingness to pay of $€ 40.268$ per QALY gained (corresponding to British pound (£) 30.000/QALY). Since there is no exact threshold value for the Danish decision-makers' willingness to pay per QALY, we applied the $£ 30.000 /$ QALY proposed by the British National Institute for Health and Care Excellence to indicate a limit for what may be considered cost-effective. ${ }^{19}$

The "control group" used in the calculations were the patients' own baseline data during the 12 months prior to surgery.

\section{Statistical Methods}

All statistical calculations on patients' symptoms were performed using Stata Statistical Computer Program 2013 (STATA; StataCorp LP, College Station, TX, USA) with only descriptive statistics performed. Quartile-quartile plots showed that data were not following normal distribution. Thus, results are given as median and full range and comparisons made with the Wilcoxon signed rank test and Mann-Whitney test. $P$-values $<0.05$ were considered statistically significant. Calculations on cost-effectiveness were made in Microsoft Excel (Microsoft, Corp, Redmond, WA, USA).

\section{Results}

\section{Study Population}

Baseline data on symptoms were available for 30 of 33 patients (Fig. 1). These included 20 patients with type $1 \mathrm{DM}$ and 10 with
Table 2. Summary Table Showing Descriptive Data in the Included Diabetes Patients in Numbers and Percent

\begin{tabular}{|c|c|}
\hline & $\mathrm{n}(\%)$ \\
\hline \multicolumn{2}{|l|}{ Gender } \\
\hline Women & $15(50)$ \\
\hline Men & $15(50)$ \\
\hline \multicolumn{2}{|l|}{ Diabetes } \\
\hline Diabetes type 1 & $20(67)$ \\
\hline Diabetes type 2 & $10(33)$ \\
\hline \multicolumn{2}{|l|}{ Death in follow-up period } \\
\hline $\begin{array}{l}\text { Cause of death: purulent meningitis (1), } \\
\text { heart arrest (1), unknown (1), } \\
\text { disseminated lung cancer (1) }\end{array}$ & $4(13)$ \\
\hline \multicolumn{2}{|l|}{ Diabetes complications before operation } \\
\hline Retinopathy & $9(30)$ \\
\hline Nephropathy & $9(30)$ \\
\hline $\mathrm{HbA} 1 \mathrm{C}$ & $74.5 \mathrm{mmol} / \mathrm{mol}$ \\
\hline Late onset diabetes complications & $6(20)$ \\
\hline Diabetic foot ulcer & $6(20)$ \\
\hline Kidney transplantation & 0 \\
\hline Dialysis & 0 \\
\hline \multicolumn{2}{|l|}{ Weight before operation (median 25 [range 15.6-33.1]) } \\
\hline Underweight & $2(7)$ \\
\hline Normal & $12(41)$ \\
\hline Overweight & $9(31)$ \\
\hline Obese & $6(21)$ \\
\hline \multicolumn{2}{|l|}{ Stomach emptying test } \\
\hline Gastric emptying scintigraphy & $5(17)$ \\
\hline Paracetamol absorption test & $18(60)$ \\
\hline Radiopaque meal test & $13(43)$ \\
\hline \multicolumn{2}{|l|}{ Post-operative complications } \\
\hline Feeding tube (permanent) & $1(3)$ \\
\hline Death & $0(0)$ \\
\hline Re-operation to adjust the position of the Stimulator & $1(3)$ \\
\hline Pain in the subcutaneous pocket & $3(10)$ \\
\hline Diffuse abdominal pain & $2(7)$ \\
\hline Small seromas & $2(7)$ \\
\hline Small hematomas & $1(3)$ \\
\hline
\end{tabular}

HbA1C, glycated hemoglobin A1C.

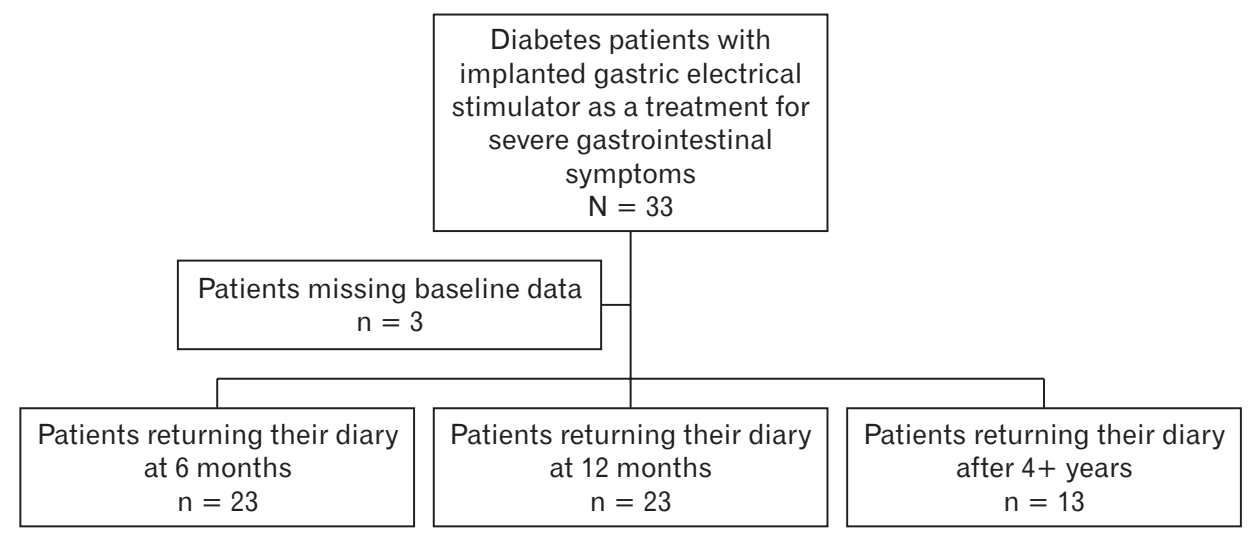

Figure 1. Flow diagram of the study cohort of diabetes patients with recurrent nausea and vomiting. Four patients died after 3, 3, 5, and 7 years of follow-up respectively. Data were not complete. Thus, 12 months follow-up included 4 patients who had not returned their diary at 3-6 months whereas 4 years + also included some patients who had not returned their diary at either 3-6 or 12 months. 
type 2 DM (Table 2). Median duration of diabetes was 21 (range 3-37) years. Median time from debut of recurrent nausea and/or vomiting until GES implantation was 4 (range 1-10) years.

Late complications to diabetes included retinopathy in 22 (73\%), nephropathy in 9 (30\%), macrovascular disease in 6 (20\%), and diabetic foot ulcer in $6(20 \%)$ patients. None had received a kidney transplant or were in dialysis treatment before the GES operation. The median follow-up was 35 (range 1-120) months. During the follow-up period; 8 (27\%) developed a diabetic foot ulcer, 5 (17\%) started dialysis treatment, and 1 (3\%) received kidney transplantation.

None of the batteries for the GES had exceeded its lifetime during the follow-up period.

\section{Complications to Surgery}

The surgical procedure was without mortality or major complications. The following minor complications were reported within 30 days. Pain near the subcutaneous pocket for the stimulator $(\mathrm{n}=3)$, diffuse abdominal pain $(\mathrm{n}=2)$, small seroma $(\mathrm{n}=2)$, and small hematoma $(n=1)$. None of the complications required surgical intervention. One patient required re-operation to adjust the position of the stimulator and another had a permanent jejunostomy feeding tube because of chronic malnutrition. Twenty-one of the patients had the current of the stimulator raised to $10 \mathrm{~mA}$ because of lack of effect. During the follow-up period four patients died of causes not related to the procedure (purulent meningitis $[\mathrm{n}=1]$, unexpected cardiac arrest $[\mathrm{n}=1]$, unknown $[\mathrm{n}=1]$, disseminated lung cancer $[\mathrm{n}=$ 1]). Death of the above occurred after $3,3,5$, and 7 years respectively.

\section{Clinical Effects}

At least $50 \%$ reduction in time with nausea was achieved in $78 \%$ of the diabetes patients after 6 months, in $30 \%$ after 12 months, and in $75 \%$ at follow-up after at least 48 (median 96 [range 48-120]) months. At least 50\% reduction in episodes with vomiting was achieved in $48 \%$ of the diabetes patients after 6 months, in $43 \%$ after 12 months, and in 69\% at follow-up after at least 48 (median 96 [range 48-120]) months.

Changes in individual symptoms are shown in Table 3. At 6 months follow-up there was a statistically significant improvement in vomiting, nausea, satiety, bloating, and general well-being. Most patients still reported improvement at long-term follow-up even though improvement of some symptoms did not reach statistical significance as the number of subjects became fewer (Table 3). The effect on symptoms did not differ between patients with normal or prolonged gastric emptying tests before implantation and GES. The median number of days in hospital was 4.5 (range 0-172) in

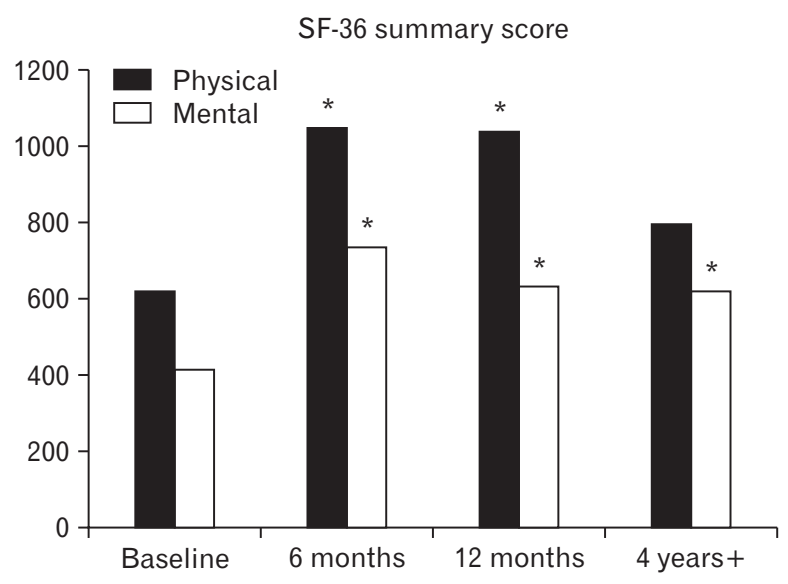

Figure 2. Short form 36 health survey (SF-36) summary scores for physical and mental health at baseline and after gastric electrical stimulation. The highest possible scores in healthy individuals are respectively 2100 for physical and 1500 for mental health. Asterisk (*) shows significant changes compared to baseline.

Table 3. Symptoms of Included Patients With Diabetes at Baseline and After Gastric Electrical Stimulation

\begin{tabular}{|c|c|c|c|c|}
\hline Symptoms & $\begin{array}{c}\text { Baseline } \\
\text { (median [range]) }\end{array}$ & $\begin{array}{c}6 \text { months } \\
\text { (median [range]) }\end{array}$ & $\begin{array}{c}12 \text { months } \\
\text { (median [range]) }\end{array}$ & $\begin{array}{l}\text { At least } 4 \text { years } \\
\text { (median [range]) }\end{array}$ \\
\hline \multirow[t]{2}{*}{ Vomiting (episodes/wk) } & $4.5[0-110]$ & $1[0-15]$ & $0.6[0-21]$ & $0[0-3.5]$ \\
\hline & & $P=0.009$ & $P=0.207$ & $P=0.004$ \\
\hline \multirow[t]{2}{*}{ Nausea (hr/wk) } & $31.2[0-112]$ & $5[0-31]$ & $11.5[0-71]$ & $0.3[0-26]$ \\
\hline & & $P<0.001$ & $P=0.003$ & $P=0.002$ \\
\hline \multirow[t]{2}{*}{ Satiety (scale $0-4$ ) } & $2.2[0-4]$ & $1.4[0-3.8]$ & $1.9[0-4]$ & $1.8[0-4]$ \\
\hline & & $P=0.003$ & $P=0.091$ & $P=0.077$ \\
\hline \multirow[t]{2}{*}{ Bloating (scale $0-3$ ) } & $2.1[0-3]$ & $1.8[0-3]$ & $1.8[0-3]$ & $1.2[0-3]$ \\
\hline & & $P=0.032$ & $P=0.292$ & $P=0.077$ \\
\hline \multirow[t]{2}{*}{ Well-being (scale 0 [best]-4 [worst]) } & $2.4[0.9-4]$ & $1[0-2.9]$ & $1.7[0-7]$ & $1.9[0.1-3.3]$ \\
\hline & & $P<0.001$ & $P=0.032$ & $P=0.583$ \\
\hline
\end{tabular}


Table 4. Incremental Cost and Effects 12 Months and 24 Months After Surgery

\begin{tabular}{lccccc}
\hline & \multicolumn{2}{c}{ Incremental cost $(€)$} & & \multicolumn{2}{c}{ Incremental effect (QALY) } \\
\cline { 2 - 3 } \cline { 5 - 6 } & 12 months & 24 months & 12 months & 0.154 \\
Mean & 10031 & 104 & 0.076 & $0.151-0.157$ \\
S5\% CI & $9630-10431$ & $-723-932$ & $0.075-0.078$ & 0.038 \\
Minimum-maximum & 4567 & -10454 & $059-19599$ & 0.019 & $0.057-0.279$ \\
ICER (€/QALY) & & & $0.018-0.131$ & 676 \\
\hline
\end{tabular}

$€$, Euro; QALY, quality adjusted life year; ICER, incremental cost-effectiveness ratio.

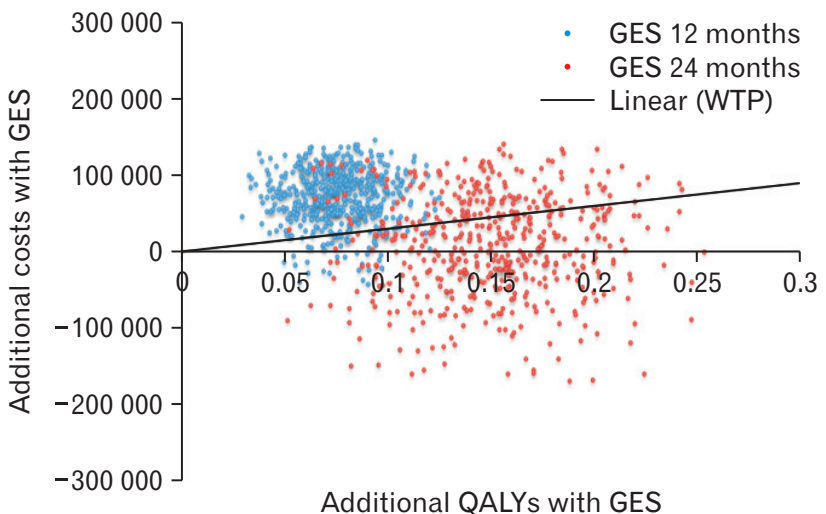

Figure 3. Bootstrap analysis showing incremental cost-effectiveness ratios at 12 months (blue) and estimated at 24 months (red) after gastric electrical stimulation (GES). Data from the 28 patients included in the analysis were re-sampled 500 times for each patient. As seen in the figure, more samples are located under the line for willingness to pay (WTP) after 24 months (red) than after 12 months (blue). Based on the analysis GES was cost-effective after 24 months. QALY, quality adjusted life year.

the 12 months before surgery, and 0 (range 0-74) during the 12 months after $(P=0.005)$.

The SF-36 summary scores for physical health and for mental health both improved significantly after 6 months, 12 months, and at long-term follow-up (Fig. 2). Before GES the median hemoglobin A1C was $75 \mathrm{mmol} / \mathrm{mol}$ (9\%) (range $45-128 \mathrm{mmol} / \mathrm{mol}$ ), and following GES it was $76 \mathrm{mmol} / \mathrm{mol}(9,1 \%)$ (range $45-121 \mathrm{mmol} /$ mol) $(P=0.358)$.

\section{Cost-utility}

Mean health economic costs were $€ 16.611$ per year at baseline and $€ 26.549$ at 12 months after GES implantation, giving an incremental cost of $€ 10.031$. The incremental cost after 24 months was $€ 104$. The mean utility value was 0.5204 at baseline and 0.5963 at 12 months follow-up, giving an incremental QALY of 0.0759 after one year with GES. The incremental QALY after 24 months was 0.1539. This gives an estimated ICER after 24 months of $€ 676$ per QALY (Table 4). The computed bootstrap analysis of the ICER after 12 months follow-up and estimated 24-months follow-up (28 patients) is shown in Figure 3.

\section{Discussion}

The present study confirms previous studies demonstrating GES to be a safe and clinically effective procedure ${ }^{8,9,20,21}$ which improves quality of life ${ }^{22}$ in a substantial proportion of highly selected patients with diabetes and severe recurrent nausea or vomiting. Our study is, however, the first to provide health economic-evaluation, and the data indicate that the procedure is cost-effective after 2 years. As the lifetime of the GES-battery is at least 10 years and the clinical effects seem to persist during follow-up, the procedure must be considered to be very cost-effective over a longer range of years.

GES has proven to be superior to placebo in 4 placebocontrolled trials in patients with diabetic, post-surgical, or idiopathic recurrent nausea and/or vomiting. ${ }^{11,23-26}$ In a double-blinded, randomized, crossover study, symptoms and quality of life improved significantly more while the stimulator was on than when off. ${ }^{11}$ However, in another study from the same group, vomiting and nausea improved both during on and off periods. ${ }^{25}$ In a doubleblinded, randomized crossover study among 32 patients with idiopathic GP, nausea and vomiting improved non-significantly both with the stimulator on and off, but with a trend towards more improvement with the stimulator on. However, the lack of a washout period between the on and off phases may have compromised the data in the study. ${ }^{23}$ Interpretation of the previously mentioned studies is hampered by a large variation in time between implantation of GES and inclusion into the randomized trials. Furthermore, the crossover design may not be appropriate for GES as the carryover effect and the necessary washout period are unknown. 
In spite of severe symptoms, only 12 of 30 of our patients had prolonged gastric emptying-time before GES. The poor correlation between symptoms and objective measures of gastric emptying is well known. ${ }^{6,27,28}$ Thus, the decision to offer the individual diabetes patient GES was based on a history of recurrent nausea and/or vomiting and not on a strict diagnosis of GP.

GES is a relatively expensive procedure, mainly because of the price of the electrode and battery, which is approximately $€ 13.000$. The immediate cost is probably the major limitation to a more common use of the procedure. A previous study comparing the use of healthcare resources among patients with idiopathic GP having either GES or medical treatment concluded that GES was the most cost-effective. This study had 3 years follow-up, but it was unfortunately not randomized. ${ }^{12}$ An open study among 37 patients, of whom 24 had diabetic GP, followed for 12 months found that days in hospital were significantly reduced after GES, but no cost-effectiveness analysis was performed. ${ }^{29}$ Our study is the first to focus on the early cost-effectiveness of GES in a population with diabetic recurrent nausea and/or vomiting. The data strongly indicate that GES is cost-effective after approximately 2 years and demonstrate that the clinical effect is maintained for a longer period of time. In a study on 188 patients, McCallum et al. ${ }^{9}$ found that the clinical improvement persisted up to 10 years.

The mechanism of action of GES remains unclear. The current intensity is too low to cause contractions of the antrum or initiate a peristaltic wave. ${ }^{11}$ No associations between changes in symptoms and gastric emptying have been found. ${ }^{11}$ Changes in central control of nausea and vomiting mediated through the vagal nerve have been suggested. Thus, vagal activity increases during GES, which may increase the threshold for discomfort during gastric distension. Data indicate increased thalamic and caudate nuclei activity during chronic high-frequency GES therapy. ${ }^{30}$ In a canine model, gastric emptying during GES correlated well with plasma motilin levels. The authors concluded that motilin levels could be important to alter gastric motility during GES. ${ }^{31}$

The main limitations in the present study are the low number of patients and that the reduced cost from days in hospital between 12 and 24 months was assumed to be the same as during the first year after GES. The "control group" used in the calculations was patients own baseline data during the 12 months prior to surgery. It is assumed that an actual control group would have the same amount of in-hospital days the following years as the patients had before surgery. A randomized placebo-controlled design has obvious advantages. However, such a design would have restricted the study period to weeks or a few months. All patients had severe symptoms and poor quality of life without sufficient relief from any other treatment attempted. The effect of GES on symptoms has been shown in previous studies, and for ethical reasons patients could only have been randomized to placebo/standard treatment for a relatively short period of time. Symptoms of gastroparesis are very variable and a much longer time is probably needed to estimate the cost/effect, especially in terms of number of days in hospital. Thus, we had to choose between a control group without GES that was followed for a relatively short period of time, or an appropriate follow-up period, which was compared to patients' baseline data.

Compared to the 2 previous studies on cost-effectiveness of GES, our study included approximately the same number of patients. As the clinical effects were maintained after more than 2 years, we find the assumption that the cost would be reduced too is valid.

First line intervention against GP is dietary modification. Patients are asked to minimize the meal-content of fat and fibers and consume frequent but smaller meals. Liquid meals are recommended because they require a minimum of mechanical processing. ${ }^{7,32}$ In addition to that, hyperglycemia per se can cause delayed gastric emptying and it is important that patients control their blood glucose levels. ${ }^{33}$

Medical treatment including antiemetics and prokinetics should be attempted. If medical therapy fails, GES or a jejunostomy feeding tube are alternatives to more extensive surgical procedures. Surgical interventions; as pyloric injection with botulin toxin, ${ }^{34} \mathrm{py}-$ loroplasty, ${ }^{35}$ and total or subtotal gastrectomy ${ }^{36}$ have been described but their effect is poorly documented.

In conclusion, our data support previous reports that GES is a safe procedure, which markedly reduces symptoms and improves quality of life in diabetes patients with recurrent nausea and/or vomiting. Our study is the first to perform an early regular cost-effective analysis of GES in diabetes patients with symptoms of GP. We found that GES reduced the days in hospital by $61 \%$ during the first year and that treatment seems to be cost-effective after a 2 -year horizon.

Financial support: The study was supported by the Novo Nordisk Foundation, Denmark (Grant No. 13159).

Conflicts of interest: None.

Author contributions: Mette W Klinge: analysing data from SF-36 and diaries, and writing article; Peter Rask: collecting data and study-design; Lene S Mortensen: collecting data and reading 
hospital records; Katrhrine Lassen: calculations in the cost-utility analysis included Fig C; Niels Ejskjaer: initiating the project, collecting data, and proofreading article; Lars H Ehlers: calculations in cost-utility analysis and proofreading article; and Klaus Krogh: study-design, writing article, and proofreading the final version of the article.

\section{References}

1. Fukami N, Anderson MA, Khan K, et al. The role of endoscopy in gastroduodenal obstruction and gastroparesis. Gastrointest Endosc 2011;74: 13-21.

2. Bharucha AE, Camilleri M, Forstrom LA, Zinsmeister AR. Relationship between clinical features and gastric emptying disturbances in diabetes mellitus. Clin Endocrinol (Oxf) 2009;70:415-420.

3. Choung RS, Locke GR 3rd, Schleck CD, Zinsmeister AR, Melton LJ 3rd, Talley NJ. Risk of gastroparesis in subjects with type 1 and 2 diabetes in the general population. Am J Gastroenterol 2012;107:82-88.

4. Uppalapati SS, Ramzan Z, Fisher RS, Parkman HP. Factors contributing to hospitalization for gastroparesis exacerbations. Dig Dis Sci 2009;54:2404-2409.

5. Horváth VJ, Izbéki F, Lengyel C, Kempler P, Várkonyi T. Diabetic gastroparesis: functional/morphologic background, diagnosis, and treatment options. Curr Diab Rep 2014;14:527.

6. DiBaise JK, Patel N, Noelting J, Dueck AC, Roarke M, Crowell MD. The relationship among gastroparetic symptoms, quality of life, and gastric emptying in patients referred for gastric emptying testing. Neurogastroenterol Motil 2016;28:234-242.

7. Parkman HP, Hasler WL, Fisher RS; American Gastroenterological Association. American Gastroenterological Association technical review on the diagnosis and treatment of gastroparesis. Gastroenterology 2004;127:1592-1622.

8. Brody F, Zettervall SL, Richards NG, et al. Follow-up after gastric electrical stimulation for gastroparesis. J Am Coll Surg 2015;220:57-63.

9. McCallum RW, Lin Z, Forster J, Roeser K, Hou Q, Sarosiek I. Gastric electrical stimulation improves outcomes of patients with gastroparesis for up to 10 years. Clin Gastroenterol Hepatol 2011;9:314-319, e1.

10. Gourcerol G, Huet E, Vandaele N, et al. Long term efficacy of gastric electrical stimulation in intractable nausea and vomiting. Dig Liver Dis 2012;44:563-568.

11. Abell T, McCallum R, Hocking M, et al. Gastric electrical stimulation for medically refractory gastroparesis. Gastroenterology 2003;125:421428.

12. Cutts TF, Luo J, Starkebaum W, Rashed H, Abell TL. Is gastric electrical stimulation superior to standard pharmacologic therapy in improving GI symptoms, healthcare resources, and long-term health care benefits? Neurogastroenterol Motil 2005;17:35-43.

13. Sculpher M, Drummond M, Buxton M. The iterative use of economic evaluation as part of the process of health technology assessment. J Health Serv Res Policy 1997;2:26-30.
14. Sculpher MJ, Claxton K, Drummond M, McCabe C. Whither trialbased economic evaluation for health care decision making? Health Econ 2006;15:677-687.

15. Medhus AW, Sandstad O, Bredesen J, Husebye E. Delay of gastric emptying by duodenal intubation: sensitive measurement of gastric emptying by the paracetamol absorption test. Aliment Pharmacol Ther 1999;13:609-620.

16. Tougas G, Eaker EY, Abell TL, et al. Assessment of gastric emptying using a low fat meal: establishment of international control values. Am J Gastroenterol 2000;95:1456-1462.

17. Brazier J, Usherwood T, Harper R, Thomas K. Deriving a preferencebased single index from the UK SF-36 Health Survey. J Clin Epidemiol 1998;51:1115-1128.

18. Sundhedsdatastyrelsen. DRG-takster 2016. Available form URL: https://sundhedsdatastyrelsen.dk/da/afregning-og-finansiering/taksterdrg/takster-2016 (accessed 25 September, 2017).

19. (NICE) NIfHaCE. Social value judgements. Principles for the development of NICE guidance. London: 2008.

20. Timratana P, El-Hayek K, Shimizu H, Kroh M, Chand B. Laparoscopic gastric electrical stimulation for medically refractory diabetic and idiopathic gastroparesis. J Gastrointest Surg 2013;17:461-470.

21. Reddymasu SC, Lin Z, Sarosiek I, Forster J, McCallum RW. Efficacy of gastric electrical stimulation in improving functional vomiting in patients with normal gastric emptying. Dig Dis Sci 2010;55:983-987.

22. Velanovich V. Quality of life and symptomatic response to gastric neurostimulation for gastroparesis. J Gastrointest Surg 2008;12:1656-1662.

23. McCallum RW, Sarosiek I, Parkman HP, et al. Gastric electrical stimulation with Enterra therapy improves symptoms of idiopathic gastroparesis. Neurogastroenterol Motil 2013;25:815-e636.

24. Frokjaer JB, Ejskjaer N, Rask P, et al. Central neuronal mechanisms of gastric electrical stimulation in diabetic gastroparesis. Scand J Gastroenterol 2008;43:1066-1075.

25. Abell TL, Johnson WD, Kedar A, et al. A double-masked, randomized, placebo-controlled trial of temporary endoscopic mucosal gastric electrical stimulation for gastroparesis. Gastrointest Endosc 2011;74:496-503, e3.

26. McCallum RW, Snape W, Brody F, Wo J, Parkman HP, Nowak T. Gastric electrical stimulation with Enterra therapy improves symptoms from diabetic gastroparesis in a prospective study. Clin Gastroenterol Hepatol 2010;8:947-954.

27. Jones KL, Russo A, Stevens JE, Wishart JM, Berry MK, Horowitz M. Predictors of delayed gastric emptying in diabetes. Diabetes Care 2001;24:1264-1269.

28. Talley NJ, Locke GR 3rd, Lahr BD, et al. Functional dyspepsia, delayed gastric emptying, and impaired quality of life. Gut 2006;55:933-939.

29. Lin Z, McElhinney C, Sarosiek I, Forster J, McCallum R. Chronic gastric electrical stimulation for gastroparesis reduces the use of prokinetic and/or antiemetic medications and the need for hospitalizations. Dig Dis Sci 2005;50:1328-1334.

30. McCallum RW, Dusing RW, Sarosiek I, Cocjin J, Forster J, Lin Z. Mechanisms of symptomatic improvement after gastric electrical stimulation in gastroparetic patients. Neurogastroenterol Motil 2010;22:161167, e50-e51. 
31. Yang M, Fang DC, Li QW, et al. Effects of gastric pacing on gastric emptying and plasma motilin. World J Gastroenterol 2004;10:419-423.

32. Moore JG, Christian PE, Coleman RE. Gastric emptying of varying meal weight and composition in man. Evaluation by dual liquid- and solid-phase isotopic method. Dig Dis Sci 1981;26:16-22.

33. Fraser RJ, Horowitz M, Maddox AF, Harding PE, Chatterton BE, Dent J. Hyperglycaemia slows gastric emptying in type 1 (insulin-dependent) diabetes mellitus. Diabetologia 1990;33:675-680.

34. Janssen P, Harris MS, Jones M, et al. The relation between symptom improvement and gastric emptying in the treatment of diabetic and idiopathic gastroparesis. Am J Gastroenterol 2013;108:1382-1391.

35. Toro JP, Lytle NW, Patel AD, et al. Efficacy of laparoscopic pyloroplasty for the treatment of gastroparesis. J Am Coll Surg 2014;218:652-660.

36. Bhayani NH, Sharata AM, Dunst CM, Kurian AA, Reavis KM, Swanstrom LL. End of the road for a dysfunctional end organ: laparoscopic gastrectomy for refractory gastroparesis. J Gastrointest Surg 2015;19:411-417. 